\title{
LA AMERICANEIDAD Y EL EXTERIOR: temores y expectativas de los turistas americanos en el extranjero
}

\section{THE AMERICANESS AND THE WORLD: Fears and expectances of Americans abroad}

\author{
Maximiliano Emiliano Korstanje (KORSTANJE, M. E.)
}

RESUMEN - En la presente nota de investigación se estudia el problema de ser estadounidense en el extranjero. Se considera que el etnocentrismo anglo combina tanto el orgullo por pertenecer a un grupo de elegidos, con el temor por ser presa de ataques extranjeros. Para validar los elementos que forman parte del anglo-centrismo, se realiza una revisión profunda del libro de Charles Robert Temple, publicado en 1961, Americans Abroad. Este verdadero documento permite visualizar con claridad los cinco componentes del etnocentrismo anglo: a) la democracia como forma de entendimiento, b) el poder adquisitivo en tanto expresión de pertenencia, c) la curiosidad por otras culturas, d) la virtud como forma ejemplar de vida, y e) el temor a viajar o residir en el extranjero.

Palabras claves: Miedo; Viajar; Extranjero; Estadounidense; Turismo.

ABSTRACT - The aim of this paper is to investigate the problem of being an American (from Unite States of America) abroad. It is considered that the Anglo ethnocentrism combines both pride for belonging to a group of selected people, with the fear of being a victim of foreign attacks. In order to validate the elements that are part of the Anglocenter, it was done a deep review on the book written by Charles Robert Temple, published in 1961, Americans Abroad. This document lets us view clearly the five Anglo ethnocentrism components: a) democracy as a way of understanding, b) the purchasing power as an expression of belonging, c) curiosity for other cultures d) virtue as a means and instance of life, and e) the fear of traveling or residing abroad.

Key words: Fear; Travel; Abroad; Foreign; American; Tourism.

\footnotetext{
Formación: Ph D. Social Psychology (Universidad de Moron). Visiting Research Fellow. School of Sociology, Universidad de Leeds, Reino Unido. Editor en Jefe de las revistas International Journal of Safety and Security in Tourism/Hospitality e International Journal of Cyber Warfare and Terrorism. Revisor de 35 revistas científicas arbitradas. Ha sido nominado a 5 doctorados honoris causa por su contribución al turismo y estudios sobre el terrorismo. Es miembro de la International Society for Philosophers, Sheffield, Reino Unido y el Tourism Crisis Management Institute de la Universidad de Florida, Estados Unidos. Docente Investigador (Universidad de Palermo, Argentina). Dirección: Larrea 1079, CP 1414. Buenos Aires, Argentina. E-mail: maxikorstanje@arnet.com.ar
} 


\section{INTRODUCCIÓN}

A pesar de su gran numero, los turistas estadounidenses son a menudo objeto de críticas, abucheos, maltratos e incluso ataques terroristas. Según información del departamento de Comercio de los Estados Unidos, en el año 2014 un total de 68.303.358 turistas de nacionalidad estadounidense dejaron el país por ocio y vacaciones. La mayoría de ellos elige países limítrofes como México 37.2\%) y Canadá (17.7\%). Un 17.4\% viajo a Europa, mientras un $10.5 \%$ eligió el Caribe. Por otro lado, Asia fue el destino de un $6.6 \%$ de estadounidenses, mientras que Latinoamérica apenas representó el $2.6 \%$.

\begin{tabular}{|c|c|c|c|}
\hline Region & Total & $\%$ Change & Market share \\
\hline Europe & 11.892 .216 & $4,2 \%$ & $17,4 \%$ \\
\hline Caribbean & 7.171 .872 & $9,6 \%$ & $10,5 \%$ \\
\hline Asia & 4.508 .517 & $4,2 \%$ & $6,6 \%$ \\
\hline South America & 1.771 .505 & $2,1 \%$ & $2,6 \%$ \\
\hline Central America & 2.697 .107 & $8,1 \%$ & $3,9 \%$ \\
\hline Oceania & 601.325 & $5,2 \%$ & $0,9 \%$ \\
\hline Middle East & 1.779 .683 & $12,7 \%$ & $2,6 \%$ \\
\hline Africa & 357.923 & $1,7 \%$ & $0,5 \%$ \\
\hline Total Overseas ${ }^{(2)}$ & 30.780 .148 & $6,1 \%$ & $45,1 \%$ \\
\hline Mexico (Total) ${ }^{(3)(\mathrm{P})}$ & 25.409 .725 & $21,9 \%$ & $37,2 \%$ \\
\hline $\operatorname{Mexico}(\text { Air })^{(2)}$ & 6.930 .590 & $11,4 \%$ & (6) \\
\hline Canada (Total) ${ }^{(4)}$ & 12.113 .485 & $0,9 \%$ & $17,7 \%$ \\
\hline Canada (Air) ${ }^{(4)}$ & 4.053 .464 & $7,5 \%$ & (6) \\
\hline North America & 37.523 .210 & $14,2 \%$ & $54,9 \%$ \\
\hline Grand Total & 68.303 .358 & $10,4 \%$ & $100,0 \%$ \\
\hline
\end{tabular}

Fuente: U.S. Department of Commerce, International Trade Administration, National Travel and Tourism Office (NTTO).

No obstante, no menos cierto parece ser que ser americano en el exterior se ha transformado en un tema de interés para diversos especialistas del turismo que se esmeran por mejorar la seguridad del viajero. En este sentido, una gran cantidad de estudiosos han llamado la atención sobre ciertos elementos culturales de Estados Unidos 
que conforman su sentido de "extraordinariedad". Los americanos se sienten y se viven como personas ejemplares y diferentes, en parte, extraordinarios tanto dentro como fuera de su país (WILDMAN, 1996; DWORKIN, 1996; GUTMANN, 2001; KREHBIEL， 2010; COLEMAN， 2013; ALTHEIDE， 2002; SKOLL， 2009; BELLESIDES, 2010; KORSTANJE, 2013). Sociólogos como Norbert Elías (1998) vislumbraron la conexión entre el racismo, la ejemplaridad y el sacrificio. La discriminación por la cual se sustenta el orden etnocéntrico requiere de un círculo cerrado a donde sólo pertenece un grupo de "elegidos" pero a la vez esa membresía se mantiene por medio de diversos sacrificios. El placer de pertenecer tiene sus costos, ya que los miembros deben demostrar ser merecedores de dicho honor. El sentido de ser un pueblo ejemplar se pone a prueba cuando los estadounidenses deben traspasar las fronteras de su mundo, para adentrarse en otras culturas con reglas nuevas de hospitalidad. En este contexto, cabe preguntarse ¿qué significa ser estadounidense fuera de Estados Unidos?

Diversas fuentes demuestran que los turistas estadounidenses demuestran mayores temores a abandonar su país que otras nacionalidades. Según los expertos, la tendencia a considerar al extranjero como un agente peligroso se aceleró luego del 11 de Septiembre (SACKET; BOTTERILL 2006, ERTUNA; ERTUNA 2009). En abordajes pasados, Geoffrey Skoll y Maximiliano Korstanje (2013) han explicado que el temor ha sido una constante en la cultura estadounidense desde antaño. Este miedo a lo diferente no solo se plasma por el racismo, sino además por las diferentes políticas gubernamentales a lo largo de los años. El gobierno estadunidense ha sistemáticamente apelado a construir un objeto de temor con el fin de adoctrinar a los cuerpos de trabajadores y a los sindicatos internos. De esa forma de comprender el extranjero no escapa a las pautas culturales de los turistas modernos, sus preferencias, estilos, y expectativas. Sociológicamente, se puede agregar que desde la guerra fría hasta nuestros días, la cultura estadounidense ha construido una imagen negativa del mundo. Ese arquetipo se refiere al resto del mundo como un espacio desestabilizado y hostil. El etnocentrismo americano no ha nacido con el 11 de Septiembre sino que se ha consolidado a través de siglos de vida política. En esta nota se examina críticamente el libro Americans Abroad, escrito y publicado originalmente por el antropólogo Charles Robert Temple en 1961. Se considera importante este texto pues articula los diversos 
elementos culturales que luego van a formar parte del discurso nacional moderno sobre lo que significa ser americano. El doble costo que implica ser parte de los "buenos muchachos" abre las puertas al inicio de una campaña expansiva donde se conjugan democracia, movilidad, y consumo cultural. Siguiendo esta línea, cuatro variables se hacen presentes en el discurso de Temple sobre lo que experimentan los turistas o los hombres de negocios americanos en el extranjero. a) La democracia como una forma de vida suprema, b) el grado de consumo y materialidad como una forma de distinción y progreso que necesita de la ostentación para subsistir, c) el miedo a ser víctima de un ataque cuando se encuentra fuera del hogar o en otro país y d) la supuesta supremacía moral de Estados Unidos y su cultura sobre el mundo. Estos elementos han sido extraídos de una lectura cualitativa del argumento de Temple sobre el extranjero, en conjunción a la literatura examinada.

\section{ESTADOS UNIDOS Y LA EXCEPCIONALIDAD}

Los analistas políticos y sociales sugieren que uno de los grandes problemas de la cultura estadounidense es la necesidad de socializar a sus miembros bajo un sentimiento de superioridad y excepcionalidad. Ya sea por su excesivo apego por el progreso y la propiedad privada como por considerarse el país cuna de la democracia, los americanos han desarrollado a lo largo de su historia un extraño etnocentrismo que no les permite comprender el mundo con claridad (FREEMAN, 2011; GONZALEZ URESTI, 2008; HILL, 1970; KOH, 2003). Jean Francois Revel advierte que este sentimiento ambivalente se debe a una proyección introducida por ciertos países europeos como Francia con vistas a generar en todo el mundo un sentimiento antiamericano con el fin de crear inestabilidad política (REVEL, 2002)

Esta idea de tutelaje garantizado por la intervención militar ha generado no pocos problemas en la política internacional. Lipset (2000) explicaba que la política exterior estadounidense es vista bajo el prisma de la lucha religiosa entre el bien y el mal, en ocasiones situación radicalizada que amerita un acto de expiación, una liberación ético-moral. No obstante, es necesario comprender que su expansionismo se encuentra justificado por la necesidad de instaurar el libre comercio y la democracia 
como formas establecidas de liberalización, de los vínculos, las personas y las mercancías. Bajo el lema que solo por medio del capitalismo se alcanza el desarrollo de los pueblos, los se intenta plasmar una ética del trabajo especial que los ha obligado a declararse de espaldas al mundo; en otras palabras, el mundo ético protestante ha creado valores internos que han permitido por medio del excepcionalismo el crecimiento imperial de los Estados Unidos, en lo comercial y militar (LIPSET, 2000).

Por su parte, Roland Inglehart (1997) advierte sobre la gran paradoja que parte de los ciudadanos americanos sientan preocupación o temor por cuestiones abstractas, cuando sus condiciones de vida han mejorado notablemente en las últimas décadas. En parte, ello sucede porque una vez que el sujeto tiene garantizadas las condiciones básicas de subsistencia, los temores comienzan a hacerse más difusos y globales. El ciudadano estadounidense se encuentra formado para verse como especial (diferente) frente al resto del mundo, admite L González Uresti (2008). Este carácter especial integra otras perspectivas que los define como superiores, innovadores, y trabajadores en tanto que enriquece su propia cultural nacional. Aun cuando sean muchos los valores que están presentes en esta cultura, los americanos valorizan la democracia, la individualidad y la ética del trabajo. La religión ha jugado un papel importante en promover un arquetipo cultural desde que los primeros colonizadores llegaron a América. El sentido que confiere el éxito económico funciona como una bendición del destino que acerca al protestante al círculo de los elegidos por Dios; la corrupción sistemática del imperio británico no solo fue funcional a una forma específica de ver el mundo, sino que ha desarrollado la necesidad de apegarse a valores morales rígidos respecto a lo que significa ser una persona virtuosa. Siguiendo este razonamiento, El profesor Gonzalez Uresti (2008) sugiere que "el moralismo utópico" de los padres fundadores no ha sido modificado a lo largo de los siglos, sino que permanece presente en su cultura desde su creación, como un sello de distinción (GONZALEZ URESTI, 2008). Su papel protagónico en política internacional en los últimos decenios ha quedado en evidencia. La figura que el arquetipo del destino tiene para los americanos los predispone a comprender las cosas que pasan en el mundo como un designio. Dichas expresiones tienen un sentido que se interpreta como una forma cultural de pertenencia. Esta clase de simbolismos no solo refleja una supuesta superioridad auto-proclamada, sino que su propia cosmología es la correcta. Por ese motivo, en materia política 
Estados Unidos intenta plasmar ideológicamente sus propios valores particulares como universales. En lo interno, es una sociedad que vive y persiste a través de muchos miedos (KORSTANJE, 2013).

No obstante, cuando se presta atención a la historia del país, uno resuelve que se han pasado por diversas etapas y posturas. Del aislacionismo original hasta la idea de una intervención sostenida, tres hechos cambiaron la forma de ver la geopolítica en sus gobernantes, la segunda guerra, Vietnam, y el 11 de Septiembre. Si la segunda gran guerra les evidenció los costos de no tomar partido, Vietnam hizo lo propio respecto a la intervención militar directa. Por su parte, el ataque al WTC ha dejado de manifiesto la peligrosidad de ser la mayor potencia mundial y militar (HRISTOULAS; SOTOMAYOR, 2008). Las diversas intervenciones reciben un trato diferente en materia interna, despertando el apoyo o el repudio de dos ramas bien definidas de ciudadanos, "aislacionistas" e "intervencionistas". Para los primeros, Estados Unidos debe garantizar los valores básicos de libertad y tolerancia, haciendo uso de la fuerza si existiese alguna amenaza. Para los segundos, la nación debe recluirse para garantizar el bienestar de sus ciudadanos. Las demás naciones actúan de forma hostil cuando sus intereses se encuentran amenazados. La política aislacionista comprende que la intervención genera una escalada de violencia que no puede controlarse, además de los costos económicos. Los intervencionistas responden, que si Estados Unidos deja un vació de poder, otra nación tomará la posta y eso representa una grave amenaza para todos. El 11/9 por su parte instaló la tesis de la "guerra preventiva" para desorganizar fuerzas que pueden potencialmente trasformarse en una amenaza (MCGOLDRICK, 2004). Uno de los aspectos más terroríficos de este ataque ha sido la idea de que cualquiera, en cualquier momento puede ser presa o víctima de un evento similar, no importa el país, mucho menos la nacionalidad. El turismo y la hospitalidad fueron industrias particularmente afectadas (KORSTANJE; CLAYTON, 2012).

Obviamente, los eventos del 11/9 han no solo acelerado dichos temores sino que crearon barreras simbólicas que no permiten comprender al otro tal cual es. Los grupos terroristas emplearon en contra de la potencia occidental sus más preciados medios tecnológicos vinculados a la movilidad y el turismo. Néstor García Canclini (1995) sugiere que la globalización fue pensada para conectar personas en un horizonte pero también para agudizar las diferencias y las asimetrías entre los pueblos. La bipolaridad 
de los términos se mezclan en construcciones imaginadas e híbridas, en donde lo local se funde con lo global, creando "lo glocal". La hegemonía central se da por la fragmentación que sostiene la propia globalización. El multiculturalismo, como construcción estadounidense, esencializa las identidades para hacer de la comunidad el principal agente de derechos. De esta forma, los comportamientos grupales quedan controlados y marcados (GARCIA CANCLINI, 1995). ¿Es la globalización un mecanismo de adoctrinamiento que crea desigualdad?

Por último, Zygmunt Bauman y Lyon (2013) reconoce que el sentido impuesto de vigilancia (en el mundo líquido) adquiere características particulares luego del 9/11. Al momento de viajar miles de turistas son escaneados, sometidos a controles biométricos del cual ni sean que son parte. A otros, de dudosa procedencia si quiera se les permite viajar. Se da una dicotomía ética entre la acumulación de datos para rastreos biográficos y las personas que manipulan esos datos. La persona ya ha dejado de contar quien es y de donde viene para someterse a un control impersonal, que por impersonal se presenta como objetivo. En ese contexto, la condición del observado se transforma en fetiche y sentimiento de excepción. Si en las viejas cárceles panópticas, la observación del prisionero se ejercía por control (bajo el lema nunca estoy solo), en la nueva sociedad de la vigilancia, el terror a ser observado se ha sublimado en la fascinación por ser noticia (BAUMAN; LYON, 2013). Este fenómeno no puede explicarse de otra forma que por una combinación de orgullo y miedo, propio del espíritu posmoderno.

\section{EL RIESGO DE SER AMERICANO EN EL EXTERIOR}

La investigación aplicada ha demostrado que los estadounidenses han desarrollado una suerte de sensibilidad frente al riesgo en comparación a otras nacionalidades. Domínguez, Baguette y Bernard (2003) entienden que el 11 de Septiembre ha calado hondo en el sentir americano generando una atmosfera de miedo e incertidumbre como nunca antes. Desde ese entonces, muchos turistas de esa nacionalidad experimentaron un aumento sustancial en los riesgos percibidos, sobre todo a la hora de viajar a países árabes. Si bien los resultados no son concluyentes, otros estudios demuestran que la nacionalidad es una variable significativa a la hora de 
comprender los riesgos percibidos por los turistas. Sacket y Botterill (2006) encuentran que los turistas estadounidenses y británicos tienen mayores reparos a la hora de viajar al extranjero que otras nacionalidades de turistas. Incluso los americanos en casi un $72 \%$ perciben mayores riesgos contra el $42 \%$ de los británicos. Similares conclusiones fueron presentadas por Ertuna y Ertuna (2009) quienes confirman que la nacionalidad es una de las variables de mayor correlación respecto al comportamiento turístico. Los investigadores sugieren como explicación que el riesgo es una construcción construida por los medios masivos de comunicación. Estos riesgos se conjugan acorde a parámetros culturales específicos pero también a situaciones geopolíticas más amplias. Los turistas de origen anglosajón podrían desarrollar un sentido del trauma con mayor agudeza ya que en todo el mundo sus compatriotas son víctimas de ataques terroristas. Las formas y estereotipos creados por los medios se tornan condicionantes a la hora de tomar una decisión respecto a determinado destino.

Por el contrario, D. Steiner (2007) enfatiza que si bien la nacionalidad puede funcionar como variable de predicción en el estudio de los riesgos, en ciertos contextos, mayor investigación es necesaria. Combinando estudios conceptuales con material empírico, Steiner advierte que el lugar de residencia se constituye con una mayor correlación respecto a la nacionalidad en si misma. Los americanos no temen al terrorismo por su calidad de americanos, sino por ser personas que habitan en un espacio urbano. La mayoría de los ataques terroristas se llevan a cabo en espacios de gran concentración de personas. Por ello, luego del 11/9 muchos americanos dejaron las grandes ciudades para vacacionar en las estancias o espacios rurales (STEINER, 2007; 2009). Fuchs y Reichel (2004) llegan a la conclusión que la religión juega un rol importante a la hora de configurar un destino como seguro o inseguro. Los protestantes y católicos perciben mayores riesgos que otros grupos religiosos. G Fuchs et al (2012) explican que la ideología es un recurso que permite la comprensión de la seguridad percibida. Partiendo de la premisa, que el primer factor de temor es la inseguridad o la poca familiaridad respecto a un territorio nuevo, los investigadores aseguran que las compatibilidades ideológicas entre el gobierno de un país y los turistas se presentan como una variable importante para comprender como funciona la mente humana respecto a que es riesgoso. Los demócratas experimentan menos riesgos que los republicanos a la hora de viajar a medio oriente. 
Gilbert Achcar (2009) establece que cada sociedad desarrolla para dentro sus propias formas de barbarie, cuyo fin último es legitimar el orden vigente. El terrorismo "global" no sería otra cosa que el choque de dos tipos de barbaries diferentes, la islámica y la occidental. En parte, el 11 de Septiembre se ha transformado en una alegoría simbólica que ha subordinado todas las identidades mundiales. Los ataques a Nueva York y Washington, las dos metrópolis de la globalización, cuestiona la "ficcionalización hegemónica" americana sobre el mundo. Las naciones no solo se identifican con Estados Unidos, sino que aceptan voluntariamente sus valores. Achcar (2009) escribe elocuentemente:

\begin{abstract}
¿Cual habría sido la reacción mundial si una matanza de masas tal se hubiera perpetrado contra otro país que no fuera Estados Unidos? - un país africano, por ejemplo -, o bien si los atentados hubieran tenido como objetivo las dos Petrona Tower gigantes de Kuala Lumpur? [...] el hecho de que los atentados del 11 de septiembre hayan golpeado Nueva York y Washington [...] explica no solamente por qué los estadounidenses han quedado tan profundamente conmocionados y conmovidos, sino también por qué el resto del mundo ha padecido una conmoción similar" (ACHCAR, 2009, p. 40).
\end{abstract}

Esta suerte de subordinación cultural, por medio de la cual la indignación se sucede en un sentido, demuestra a grandes rasgos el poder de la ideología. Achcar denomina a este sentir colectivo, la compasión narcisista. Un ciudadano plagado de deudas, problemas y obligaciones puede reanudar su compromiso con el grupo de los "elegidos" para absorber la frustración de sus propias carencias, pero a la vez de aquellas producidas por ese grupo al cual desea pertenecer.

Los ataques a los ciudadanos que salen del centro no tiene el mismo impacto desde lo simbólico que los ataques perpetrados hacia la periferia. El 11 de Septiembre ha generado un quiebre que ha jerarquizado la importancia de las víctimas. Asesinar a un turista Americano en el Congo, no tiene el mismo impacto que planificar un atentado en Buenos Aires. De hecho, Korstanje y Skoll (2012) han demostrado que los argentinos a pesar de haber sufrido un ataque terrorista con casi 91 muertes, hoy vinculan al terrorismo con una cuestión estadounidense. Los autores establecen que la ideología juega un papel importante no solo asignando un rol a cada persona, sino valores comparables a otros que hacen a la propia identidad. En forma reciente, Wolff y Larsen (2013) encuentran que los atentados terroristas perpetrados en suelo Noruego (Oslo) en 2011 donde murieron más de 69 personas, no ha suscitado un alto impacto a 
corto o largo plazo en la demanda turística internacional. De alguna forma, incluso los noruegos perciben a su país como más seguros que otros. Si bien bajo ciertas circunstancias el riesgo no parece tomar la misma dimensión dependiendo del contexto, se puede afirmar que el 9/11 ha abierto la puerta a una jerarquización del riesgo, donde la nacionalidad de la víctima juega un rol importante.

Por último pero no por ello menos importante, algunos investigadores han descubierto que el terrorismo ha sido simbólicamente identificado a la vida en las grandes ciudades. El turismo y sus flujos no quedan vedados por el terrorismo, sino que muta hacia nuevas formas, hacia nuevos destinos. Aquellas personas que por proximidad geográfica viven cerca de Nueva York experimentaron mayores ansiedades luego del 9/11 (FLOYD, PENNINGTON-GRAY, 2003; WONG, YEH, 2009). Korstanje y Olsen (2011) examinaron el discurso de varias películas de terror post 9/11. Los autores encuentran que el evento ha generado un cambio sustancial en la psiquis americana y en la manera en que se ruedan este tipo de trabajos. Centrados en el análisis de discurso de la Masacre en Texas, Hostel entre otras, se observa que el americanismo se encuentra condicionado por una combinación de orgullo y temor. Al mismo momento que los turistas estadounidenses son admirados como verdaderos arquetipos de la tolerancia, la civilización y la democracia, su propia existencia se encuentra comprometida por agentes del mal, sádicos que disfrutan asesinando turistas americanos en países de la periferia de Europa. No solo la falta de hospitalidad dispara las raíces simbólicas del mal, el mundo fuera de Estados Unidos es presentado como un lugar extremadamente peligroso. Ello configura la base para la creación de un discurso etnocéntrico pues se concibe al turista americano como de mayor valía que otros grupos. Configurando al resto del mundo como un espacio hostil, y recreando una mirada etnocéntrica del otro no estadounidense, el discurso de la extraordinariedad se encuentra encerrado en un dilema de difícil solución. Por un lado, permite la intervención de Estados Unidos en nuevos mercados mundiales acorde a sus propios intereses y generando un gran clima de resentimiento que luego se vuelca hacia los turistas de esa nacionalidad. Por el otro, los turistas, la mayoría de ellos educados en la premisa política del buen ciudadano que respeta la democracia, comprenden la hostilidad hacia ellos como un signo de autoritarismo. Como se verá en el texto de Temple (1961), a 
continuación, este círculo vicioso pone al viajero en el papel de una doble víctima, es rehén de su estado y del terrorismo.

\section{EL TRABAJO DE CHARLES ROBERT TEMPLE}

Para una correcta lectura de su obra, es importante señalar que Charles Robert Temple (1961) es un antropólogo estadounidense conocedor de seis idiomas diferentes, y cuya amplia experiencia por el mundo lo lleva a escribir el libro Americans Abroad (1961), el cual es un trabajo destinado a explicar los diversos cambios que sufre un estadounidense cuando debe salir de su país ya sea por turismo o por trabajo. Por lo expuesto, este documento escrito en plena guerra fría no solo representa un campo fértil para comprender como se articula el mensaje de la "americaneidad", sino también como funciona el etnocentrismo dentro del concepto de lo ejemplar antes descrito. La importancia de una lectura detallada de los diversos consejos que da Temple sobre lo que debe o no hacer un americano en el exterior no es un tema menor.

El final de la segunda guerra pone a Estados Unidos como uno de los mayores beneficiarios. Miles de personas comienzan no solo a ver su poder adquisitivo enriquecido, sino a utilizar su tiempo libre para viajar por diversas regiones y por diferentes geografías. Los turistas americanos son para Temple embajadores de la cultura estadounidense a la vez que ejemplares ciudadanos socializados en una de las más puras democracias:

Turning up in every part of the globe, these Americans are our informal representative to the other peoples of the world. What we are and what our democracy means will be judged by their action and reaction long after the formal speeches and actions of politicians have been forgotten. This was not always so, and once John Doe, an American living in a foreign country, might have been looked upon by the people about him as just another foreigner, with little or no reference to his national background (TEMPLE, 1961, p. 8).

Para Temple como muchos otros cientistas sociales de la época, la democracia es vista como un legado sublime que lleva al mundo al entendimiento y a la armonía de corte político. Empero para ello, el viajero debe demostrar porque se encuentra como parte del grupo de los elegidos, y comportarse como mandan las normas y las buenas 
costumbres. En su pensamiento, los turistas no son cuestionados o juzgados por las políticas internacionales de su estado, sino por su propia conducta. El libro, no huelga decir, se encuentra plagado de ejemplos prácticos, vivencias y consejos sobre lo que debe hacer un buen estadounidense cuando está fuera de su patria. Si bien, reconoce que muchos compatriotas son renuentes a aprender una lengua extranjera, enfatiza en que hablar bien ciertas lenguas puede facilitar muchas cuestiones, sobre todo cuando alguien está en apuros o incluso para hacer buenos negocios. El factor material es un aspecto interesante dentro del discurso de Temple. El ciudadano americano, en términos de Max Weber $(1958 ; 1964 ; 1995)$, debe demostrar que la supuesta superioridad moral se corresponde con un grado de riqueza acumulada (éste es el génesis capitalista). Para no ser acusado de etnocéntrico, nuestro antropólogo se preocupa por aquellos viajeros que no ha tenido el tiempo o las ganas suficientes en interesarse por comprender y aprender sobre otras costumbres y culturas. La búsqueda de la novedad parece ser el segundo aspecto relevante en el texto examinado:

[...] there are certain fundamental experiences which have to be met by everyone who leaves his own country to live elsewhere. Going abroad means giving up home in spiritual a well as physical sense; it means acquiring a new kind of education; it means adopting new attitudes and points of view about foreigners and their ways; it means assessing one's own values in light of other's people's value and standards (TEMPLE 1961, p. 15).

Los turistas parecen no esconder su fascinación por ver como viven ciertas poblaciones marginales o empobrecidas. Ello sucede porque quieren reafirmar no solo su identidad sino su sentido de la supremacía. En uno de sus pasajes, Temple (1961, p. 21) afirma:

[...] slumming is neither possible nor intelligent. As Americans, living in a technically advanced, affluent society, we tend to downgrade those peoples of the world who have not participated in the industrial revolution and whose economies are inadequate to their population's needs.

Y ello sucede debido a que Estados Unidos es un país fértil, cuya economía rica en recursos naturales ha florecido gracias a la virtud industrial y a la maquinaria tecnológica. El sentido de la "americaneidad" debe ser expuesto en términos de lo que significa la Ciencia, el trabajo duro y el descanso. Cuando esta cuestión no queda del todo clara, el autor recurre a comparar la vida de un ciudadano estadounidense y la de 
un aborigen. Respecto al segundo, su posición queda excluida de la sociedad americana. El atraso de los "aborígenes" se debe a la falta de interés por el trabajo industrial. Seguramente, Temple ignora no solo el grado de opresión de las tribus aborígenes en todo el continente, sino la gran cantidad de reservas dentro de su propio país.

En su texto, Temple rechaza de plano que Estados Unidos fuese un imperio opresor. Según su visión, su posición como principal potencia democrática del planeta se debe al grado de virtuosismo de los funcionarios. El tercer elemento propio del etnocentrismo, la virtud hace aparición en el siguiente párrafo:

[...] most judges can't be bribed, few men sell their votes; the majority of Americans reject attempts to limit minority rights; and while a poor man may rarely lunch with a rich one, both can do pretty much what they like otherwise (TEMPLE, 1961, p. 30).

Para poder comprender el último de los elementos, la virtud se hace un componente esencial. Ella permite crear un puente entre el grupo sagrado y el otro profano. Ciertamente, Temple no da cuentas de la opresión que han recibido grupos étnicamente minoritarios dentro de los Estados Unidos, como así tampoco en lo radical de su afirmación. Sin la virtud, el mundo de los elegidos puede presentarse como exclusivo de pocos. Cuando sugiere que los turistas deben abandonar a su país para viajar por negocios o por placer, escribe que el mundo no siempre se encuentra plagado de culturas bárbaras como algunos suponen. Para poder lograr una mejor adaptación al medio, el viajero debe leer las guías, magazines y periódicos orientados a dar asistencia a los turistas. Temple agrega, el viaje es o debería ser comprendido como un "arte" donde el viajero desarrolla nuevas habilidades para lidiar con diferentes temas o problemas. El conocimiento (know-how) el último de los componentes del etnocentrismo anglo, es importante pues el mundo se presenta como un espacio hostil, ajeno, una ruptura epistémico irreconciliable con lo cognoscible.

Los capítulos del libro restantes, consisten en meros ejemplos de personas que ya viajaron y de los problemas que debieron de enfrentar. Hasta aquí se ha descrito el argumento de Temple tal y cual fue formulado por él mismo. Su forma de concebir la americaneidad pone a los ciudadanos de ese país en el pedestal de la pirámide respecto de otros grupos y nacionalidades. Los intereses materiales o financieros del lucro marcan el signo de quien pertenece o no al mundo de los elegidos. No obstante, esta 
misma forma de pensar genera no pocos problemas para quienes salen de Estados Unidos. En este punto el discurso anglo-céntrico desdibuja la relación entre causas y consecuencias. No advierte a sus propios ciudadanos sobre las políticas que el estado lleva en determinadas áreas, sino que se limita a señalar que espacio es considerado seguro y cual no. La responsabilidad de un americano de viajar a medio oriente no corresponde a su estado, mucho menos a sus políticas en la región. Siendo actores políticos por naturaleza, los turistas se transforman sin quererlo en víctimas dobles, del terrorismo y de su propio estado. El ciudadano es comprendido, para ambos, acorde al valor que puede generar. Para el estado como forma estereotipada de consumo, para el terrorista con el valor simbólico (que genera su sufrimiento) para entablar negociaciones más eficientes. Si bien el 11/9 precipitó un cambio significativo en la forma en que el americano veía al extranjero, esta tendencia de orgullo y temor se encuentra presente desde su fundación política y cultural.

\section{CONCLUSIÓN}

Cabe aclarar, todos los pueblos en mayor o menor medida mantienen formas de etnocentrismo que permiten proteger su afinidad identitaria, y también que el extranjero pone a prueba esas construcciones. El sentido de lo que significa ser "americano en el extranjero" presenta una divergencia conceptual entre la atracción y la repulsión. Para comprender su lógica, es necesario mencionar el Anglo-etnocentrismo fagocita la idea de excepción frente al resto del mundo que los sitúa en un pedestal por elevación. Se comparan respecto al resto, como más inteligentes, democráticos, competitivos y virtuosos. Esta forma de comprender al otro determina un círculo de exclusión de todos aquellos quienes no comprenden estas supuestas características. Admirar a los turistas americanos es conferirles un mayor valor lo cual implícitamente acepta su hegemonía sobre el mundo. Empero, ser parte de un grupo de elegidos tiene su costo. Como se ha mencionado, cuando los americanos cruzan sus fronteras el orgullo se transforma en pánico. El turista pasa a ser un blanco fácil de aquellos que por motivos que poco se comprenden "odian la vida americana". Los destinos turísticos son diseñados y acondicionados acorde al grado de seguridad percibida (riesgo) que puedan brindarles a 
los turistas americanos. Este discurso que puede verse en filmes como Hostel, o Masacre en Texas re-categoriza la ciudadanía estadounidense reconstruyendo al mundo como un espacio hostil y sumamente peligroso. A la vez que el turista es torturado por el villano, su valor incrementa. Sin ir más lejos, en Hostel es de capital interés reparar en el hecho de los turistas americanos cotizan mucho más que los de otra nacionalidad.

Para concluir, los turistas no solo son consumidores crónicos que viajan sino que transmiten un código político específico de sus respectivas culturas. El pacto de la hospitalidad recuerda que este encuentro se corresponde con una serie de tensiones de uno u otro lado. Cada estado-nación construye un discurso especial, como una historia que es contada una y otra vez. Esta narrativa permite comprender las cosas que suceden en el mundo, pero a la vez alimenta el propio etnocentrismo. El turismo no solo pone a estos discursos (políticos) enfrentados o en tensión dialéctica, sino que permite inferencias para comprender cuestiones de ambas culturas que de otra forma serían ignoradas. El etnocentrismo americano combina orgullo con temor, focalizando en el valor y el costo de lo que significa ser estadounidense. Si por un lado fomenta la libertad dentro de sus fronteras, en lo exterior (ese mismo sentido de ejemplaridad) le permite intervenir otras naciones soberanas. Como resultado, se genera una escalada de hostilidades que ponen al turista como rehén. Cualquier acto de agresión frente al turista es comprendido como un acto de vandalismo en contra de la democracia misma. Esta quimera discursiva el estado americano construye identidad a través del conflicto.

\section{REFERENCIAS}

ACHCAR, G. El Choque de las Barbaries. Terrorismos y Desorden Mundial. Buenos Aires: Capital Intelectual, 2009.

ALTHEIDE, D. Creating Fear: News and the Construction of Crisis. Hawthorne NY: Aldine de Gruyter, 2002.

BAUMAN, Z. y LYON, D. Vigilancia Liquida. Buenos Aires: Paidos, 2013.

BELLESILLES, M. A. 1877: America's Year of Living Violently. New York: The New Press, 2010. 
COLEMAN, S. Actors of History? Religion, Politics, and Reality within the Protestant Right. In: LINDQUIST, G.; HANDELMAN, D. (org.). America. Religion, Politics \& Globalization. New York: Berghan Book, 2013, p. 171-188.

DOMINGUEZ, P.; BURGUETTE, E.; BERNARD, A. Efectos del 11 de Septiembre en la hotelería Mexicana: reflexión sobre la mono-dependencia turística. Estudios y Perspectivas en Turismo, v. 12, n. 3-4, 2003, p. 335-348.

DWORKIN, R. Freedom's Law: the moral reading of the American Constitution. Massachusetts: Harvard University Press, 1996.

ELIAS, N. La Civilización de los Padres y otros Ensayos. Bogotá: Editorial Norma, 1998.

ERTUNA, C.; ERTIMA, Z. I. The Sensitivity of German and British tourists to new shocks. Tourism Review. v. 64, n. 3, 2009, p. 19-27.

FLOYD, M.; PENNINGTON GRAY, L. Profiling Risk: perception of tourist. Annals of Tourism Research, v. 31, n. 4, 2003, p. 1051-1054.

FUCHS, G.; Y REICHEL A. Cultural differences in tourist destination risk perception: an exploratory study. Tourism (Zagreb), v. 52, n. 1, 2004, p. 21-37.

FUCHS, G.; URIELY, N.; REICHEL, A.; MAOZ, D. Vacationing in a terror-stricken destination: Tourists' risk perceptions and rationalizations. Journal of Travel Research, v. 52, 2012, p. 1-10.

FREEMANN, M. Human Rights. An interdisciplinary Approach. Cambridge: Polity Press, 2011.

GARCIA-CANCLINI, N. Consumidores y Ciudadanos. Buenos Aires: Grijalbo, 1995.

GONZALEZ URESTI, S. La Política Exterior: ¿hegemonía o imperio global? In: FERNÁNDEZ DE CASTRO; BLACKMORE, H. (org.) ¿Qué es Estados Unidos? México: FCE, 2008, p. 263-304.

GUTMANN, A. Introduction. In: IGNATIEFF, M. (org.) Human rights, as politics and idolatry. New Jersey: Princeton University Press, 2001, p. Vii-xxviii.

HILL, C. God's Englishman. Oliver Cromwell and the English Revolution. Middlesex: Penguin Books, 1970.

HRISTOULAS, A.; SOTOMAYOR, A. La Política de Seguridad y Defensa: historia, presente y retos. In: FERNÁNDEZ DE CASTRO; BLACKMORE, H. ¿Qué es Estados Unidos? México: FCE, 2008, p. 304-348. 
INGLEHART, R. Modernization and Postmodernization. Cultural, Economic and political change in 43 Societies. New Jersey: Princeton University Press, 1997.

KOH, H. H. On American Exceptionalism. Stanford Law Review, p. 1479-1527, 2003.

KORSTANJE, M. Empire and Democracy, a critical reading of Michael Ignatieff. Nómadas: revista crítica de Ciencias Sociales y Jurídicas, n. 38 (II), 2013, p.69-78.

KORSTANJE, M.; CLAYTON A. Tourism and Terrorism, Conflicts and Commonalities. Worldwide Hospitality and Tourism Themes, v. 4, n. 1. 2012. p. 825.

KORSTANJE, M. E.; SKOLL, G. New York-Buenos Aires: Different Solutions to the Same Problem: Terrorism and Citizenry. Rosa dos Ventos, v. 4, n. 1, 2012, p. 1-9.

KORSTANJE, M. E.; OLSEN, D. H. The discourse of risk in horror movies post 9/11: hospitality and hostility in perspective. International Journal of Tourism Anthropology, v. 1, n. 3, 2011, p. 304-317.

KREBHIEL, K. Pivotal politics: A theory of US lawmaking. University of Chicago Press, 2010.

LIPSET, M. S. El Excepcionalismo norteamericano: una espada de dos filos. México: FCE, 2000.

MCGOLDRICK, D. From'9-11'to the'Iraq War 2003': international law in an age of complexity. Hart Publishing, 2004.

REVEL, J. F. Anti-americanism. San Francisco: Encounter Books, 2002.

SACKETT, H.; BOTTERILL, D. Perception of International Travel Risk: an exploratory study of the influence of proximity to terrorist attack. E-review of tourism Research, v. 4, n. 2, 2006, p. 44-49.

SKOLL G. Contemporary Criminology and Criminal Justice Theory. Evaluating justice Systems in Capitalist Societies. New York: Macmillan, 2009.

SKOLL, G. R.; KORSTANJE, M. E. Constructing an American fear culture from red scares to terrorism. International Journal of Human Rights and Constitutional Studies, v. 1, n. 4, 2013, p. 341-364.

STEINER, C. Political instability, Transnational Tourist Companies and Destination Recovery in the Middle East after 9/11. Tourism and Hospitality Planning \& Development, v. 4, n. 3, 2007, p. 169-190.

TEMPLE, R. C. Americans Abroad. New York: Bold Face Books, 1961.

WEBER, M. Essays in Sociology. New York: Oxford University Press, 1958. 
Economía y sociedad: esbozo de sociología comprensiva. México: FCE, 1964. 1995.

La Ética Protestante y el Espíritu del Capitalismo. Barcelona: Península,

WOLFF, K.; LARSEN, S. Can Terrorism make us feel Safer? Risk Perception and worries before and after the July $22^{\text {nd }}$ attacks. Annals of Tourism Research. In press, 2013.

WILDMAN, S. M. Privilege revealed: How invisible preference undermines America. New York: NYU Press, 1996.

WONG, J. Y.; YEH, C. Tourist Hesitation in Destination decision Making. Annals of Tourism Research, v. 36, n. 1, 2009, p. 6-23.

Recebido em: 28-08-2014.

Aprovado em: 27-09-2014. 